\title{
Tensile and fracture properties of NiAl/Ni micro-laminated composites prepared by reaction synthesis
}

\author{
Hee Y. Kim \\ Department of Materials Science and Engineering, Korea Advanced Institute of Science and \\ Technology, Yuseong-gu, Daejeon 305-701, Korea \\ Dong S. Chung \\ Department of Materials, Daegu Polytechnic College, Seo-gu, Daegu 681-280, Korea \\ M. Enoki \\ Department of Materials Engineering, The University of Tokyo, Bunkyo-ku, Tokyo 113-8656, Japan \\ Soon H. Hong ${ }^{\text {a) }}$ \\ Department of Materials Science and Engineering, Korea Advanced Institute of Science and \\ Technology, Yuseong-gu, Daejeon 305-701, Korea
}

(Received 30 September 2005; accepted 5 January 2006)

\begin{abstract}
The mechanical properties of NiAl/Ni micro-laminated composites with highly gradient microstructure have been investigated. Two types of composites with different gradient microstructures were prepared by reaction synthesis. Intermetallics of type I and type II composites mainly consisted of Al-rich $\mathrm{Ni}_{0.45} \mathrm{Al}_{0.55}$ with variable thickness and $\mathrm{Ni}$-rich $\mathrm{Ni}_{0.58} \mathrm{Al}_{0.42}$ with similar thickness, respectively. As intermetallic volume fraction increased, yield strength of type II followed the rule-of-mixture well, while that of type I deviated due to the composition variation of intermetallic phases. Fracture toughness of type II was higher than that of type I, and all showed $K_{\mathrm{R}}$ curves with upward curvature by large-scale bridging. Even though the relative strength of constituent phases in intermetallic/metal laminates was not constant due to the gradient microstructure, the fracture mode transition showed similar behavior to that of metal/ceramic laminates.
\end{abstract}

\section{INTRODUCTION}

The intermetallic/metal laminated composites were suggested by various researchers to improve the brittleness of intermetallic at ambient temperature. ${ }^{1-6}$ These composites offer an attractive combination of mechanical properties distinct from the separate constituent phases, e.g., high toughness of the metal coupled with low density, high oxidation resistance, and high strength at elevated temperature of the intermetallic.

Reaction synthesis has been used for the fabrication of intermetallic/metal laminated composites and had many advantages such as near-net shaping, crucible-less processing of materials with high melting point, microscopic compositional homogeneity, and low cost compared with conventional processing using melting and casting methods. It has been successfully manufactured by alternatively stacked commercial elemental foils such as $\mathrm{Ni}, \mathrm{Ti}$, $\mathrm{Nb}, \mathrm{Fe}$, and $\mathrm{Al} .^{7-11}$ Generally, microstructures obtained

\footnotetext{
a) Address all correspondence to this author.

e-mail: shhong@kaist.ac.kr

DOI: 10.1557/JMR.2006.0154
}

by reaction synthesis have composition gradients along the direction perpendicular to stacking, and these anisotropic and heterogeneous microstructure can highly affect the mechanical properties of intermetallic/metal micro-laminated composites. ${ }^{9}$

Most of the theoretical studies on mechanical properties of micro-laminated composites have been focused on the fracture mode of the metal/ceramic systems, assuming that the ceramic layers have a uniquely determined strength, any elastic mismatch between the metal and ceramic component can be ignored, and linear elastic fracture mechanics (LEFM) can be applied. Cao and Evans ${ }^{12}$ studied the stress fields around a crack in $\mathrm{Al}_{2} \mathrm{O}_{3}$ / $\mathrm{Al}$ system by finite element analysis. From their results, two limits were identified for a crack located in a brittle layer with its tip incident upon a ductile layer: smallscale bridging (SSB) limit wherein the plastic zone extends completely through the ductile layer but only a small distance along the layer and a large-scale bridging (LSB) limit, or shear lag limit, wherein the plastic zone extends a relatively large distance normal to the crack. Shaw et al. ${ }^{13}$ observed experimentally the stress field around crack tip and used LEFM to calculate the stress 
field according to ceramic volume fraction. Huang and Zhang ${ }^{14,15}$ considered a single ductile bridging metal layer as a Dugdale element with constant crack closure traction, which was confined to the crack plane and taken as approximately three times the metal yield strength from considerations of local constraint. Hwu and Derby ${ }^{16}$ suggested the composite model combining the existed LEFM with simple shear-lag solution operating at lower values of normalized metal constrained yield strength in three metal/ceramic laminated composites: $\mathrm{Al} / \mathrm{Al}_{2} \mathrm{O}_{3}, \mathrm{Cu} / \mathrm{Al}_{2} \mathrm{O}_{3}, \mathrm{Ni} / \mathrm{Al}_{2} \mathrm{O}_{3}$.

$\mathrm{Metal} /$ ceramic laminates usually fabricated by diffusion bonding under hot pressing conditions had more discrete interfaces than intermetallic/metal laminates and have been uniquely modeled with the assumption of constant intrinsic property of each phase. However, intermetallic/metal systems prepared by reaction synthesis have highly gradient microstructure. Existing models assuming constant intrinsic property could not predict the properties of intermetallic/metal laminates well any more. In this study, we have examined tensile properties, crack tip opening displacement (CTOD), and $K_{\mathrm{R}}$-curve behavior of $\mathrm{NiAl} / \mathrm{Ni}$ micro-laminated composites. Intermetallic fracture strength was deduced from the analysis of multiple cracking behavior during tensile loading of microlaminated composites. Fracture toughness improvement due to the bridging of ductile metal layer was studied quantitatively based on the LSB model. Fracture mode transition from multiple cracking to single cracking according to intermetallic volume fraction in $\mathrm{NiAl} / \mathrm{Ni}$ micro-laminated composites was experimentally investigated and explained by combined model of LEFM and shear lag.

\section{EXPERIMENTAL}

\section{A. Preparation of NiAl/Ni micro-laminated composites}

Two types of micro-laminated composites using commercially pure $(99.0 \%$ min.) $\mathrm{Ni}$ and $\mathrm{Al}$ foils (10-100 $\mu \mathrm{m}$, Goodfellow Co.) were fabricated to investigate the effect of thickness and thickness ratio. Type I was made by using various $\mathrm{Al}$ thickness $(100,50$, and $25 \mu \mathrm{m})$ with constant Ni thickness $(100 \mu \mathrm{m})$, and type II was made by using various Ni thickness $(75,50,25 \mu \mathrm{m})$ with constant Al thickness $(10 \mu \mathrm{m})$ (Table I). These foils were cut into $50 \times 50 \mathrm{~mm}$ squares and cleaned in the ultrasonic bath with acetone for $30 \mathrm{~min}$. Alternatively stacked foils were heat-treated by three thermomechanical steps: (i) diffusion bonding, (ii) reaction synthesis, and (iii) post-heat treatment, as mentioned in our earlier work. ${ }^{3-6}$

Both ends of the stacked pile were thermally insulated by zirconia felt (ZYF-100) to minimize heat loss during reaction. Stacked piles were diffusion bonded for $30 \mathrm{~min}$ at $600{ }^{\circ} \mathrm{C}$ under $10 \mathrm{MPa}$ of applied stress in the vacuum hot press. Diffusion bonded specimens were heated to $750{ }^{\circ} \mathrm{C}$ and held at this temperature for $1 \mathrm{~h}$. No pressure was applied to the specimens during reaction at $750{ }^{\circ} \mathrm{C}$. Post-heat treatment under $100 \mathrm{MPa}$ pressure was employed to close shrinkage cavity during solidification of the transient liquid phase and to remove any Kirkendall porosity during solid-state diffusion. The volume fractions of each phases in laminated composites were analyzed by an image analyzer through optical microscope (Leica DMLM). To identify crystal structure and chemical composition of each constituents on the microstructure, energy dispersive spectroscopy (EDS; Oxford) and XRD (Rigaku, $\mathrm{Cu} \mathrm{K}_{\alpha}$ ) were used.

\section{B. Characterization of mechanical properties}

Tensile test specimens were machined from the reaction-bonded micro-laminated composites with dimensions of $5 \mathrm{~mm}$ width, $5 \mathrm{~mm}$ height, and $50 \mathrm{~mm}$ length by electrodischarge wire cutter. Lateral side of micro-laminated composites were mirror-surface polished by $0.25-\mu \mathrm{m}$ diamond paste to investigate multiple cracking during tensile loading. Tension tests were performed in static testing machine (Instron 5583) with loading speed of $0.1 \mathrm{~mm} / \mathrm{min}$. Strain was measured by extensometer with the gauge length of $10 \mathrm{~mm}$. Fractured surface of each specimens were examined by scanning electron microscopy (SEM).

Specimens for fracture toughness tests in crack arrester direction were machined with dimensions of $4 \mathrm{~mm}$ width, $4 \mathrm{~mm}$ height, and $30 \mathrm{~mm}$ length. Each side of crack arrester direction was mirror polished by $0.25-\mu \mathrm{m}$ diamond paste. Notching was introduced with a diamond

TABLE I. Summary of initial foil thickness and final microstructure of micro-laminated composites prepared by reaction synthesis.

\begin{tabular}{|c|c|c|c|c|c|c|c|}
\hline & \multicolumn{2}{|c|}{ Initial thickness } & \multicolumn{2}{|c|}{ Final thickness $(\mu \mathrm{m})$} & \multicolumn{2}{|c|}{ Volume fraction } & \multirow[b]{2}{*}{ Main intermetallic phases } \\
\hline & $\mathrm{Ni}(\mu \mathrm{m})$ & $\mathrm{Al}(\mu \mathrm{m})$ & Metal & Intermetallic & Metal & Intermetallic & \\
\hline \multirow[t]{3}{*}{ Type I } & 100 & 25 & 70 & 38 & 0.65 & 0.35 & $\mathrm{Ni}_{0.45} \mathrm{Al}_{0.55}$ \\
\hline & & 50 & 65 & 53 & 0.55 & 0.45 & \\
\hline & & 100 & 57 & 70 & 0.45 & 0.55 & \\
\hline \multirow[t]{3}{*}{ Type II } & 75 & 10 & 47 & 18 & 0.72 & 0.28 & $\mathrm{Ni}_{0.58} \mathrm{Al}_{0.42}, \mathrm{Ni}_{3} \mathrm{Al}$ \\
\hline & 50 & & 33 & 20 & 0.63 & 0.37 & \\
\hline & 20 & & 13 & 18 & 0.33 & 0.67 & \\
\hline
\end{tabular}


blade in the crack arrester direction of micro-laminated composites, and the crack had root radius of about 30$50 \mu \mathrm{m}$. CTOD tests were conducted under ASTM E399 and E1290 standards. ${ }^{17,18}$ Displacements were measured by crack opening displacement gage with gauge length of $10 \mathrm{~mm}$ mounted through attachable knife edge and loading rate was $0.1 \mathrm{~mm} / \mathrm{min}$. Stress intensity factors $K_{\mathrm{Q}}$ were calculated by Eq. (1) using the specimen geometry of ASTM E399. ${ }^{17}$

$$
\begin{aligned}
K_{\mathrm{Q}}= & \frac{P_{\mathrm{Q}} S}{B S^{3 / 2}} \\
& \frac{3 \alpha^{1 / 2}\left[1.99-\alpha(1-\alpha)\left(2.15-3.93 \alpha+2.7 \alpha^{2}\right)\right]}{2(1+2 \alpha)(1-\alpha)^{3 / 2}},
\end{aligned}
$$

where $\alpha=a_{0} / W$ and $P_{\mathrm{Q}}, B, S, W$, and $a_{0}$ are load, thickness, span, width, and crack length, respectively. $K_{\mathrm{R}^{-}}$ curve tests were performed with manually loaded 3-point bend tester in the SEM (Hitachi S-2150). Crack length increase $(\Delta a)$ was directly measured during loading. $K_{\mathrm{R}^{-}}$ curves were obtained substituting $a_{0}+\Delta a$ instead of $a_{0}$ from Eq. (1).

\section{RESULTS AND DISCUSSION}

\section{A. Microstructure of $\mathrm{NiAl} / \mathrm{Ni}$ micro-laminated composites}

Figure 1 shows the typical microstructures of heattreated intermetallic/metal micro-laminated composites. By EDS and XRD analysis, type I micro-laminated composites using $100 \mu \mathrm{m}$ Ni foil had the phase sequences of $\mathrm{Ni}_{3} \mathrm{Al} / \mathrm{Ni}_{0.58} \mathrm{Al}_{0.42} / \mathrm{Ni}_{0.45} \mathrm{Al}_{0.55} / \mathrm{Ni}_{0.58} \mathrm{Al}_{0.42} / \mathrm{Ni}_{3} \mathrm{Al}$, and type II micro-laminated composites using $10 \mu \mathrm{m} \mathrm{Al}$ had the phase sequences of $\mathrm{Ni}_{3} \mathrm{Al} / \mathrm{Ni}_{0.58} \mathrm{Al}_{0.42} / \mathrm{Ni}_{3} \mathrm{Al}$. Initially, $\mathrm{NiAl}_{3}$ and $\mathrm{Ni}_{2} \mathrm{Al}_{3}$ intermetallics were formed after the reaction synthesis of $\mathrm{Ni}-\mathrm{Al},{ }^{5,19}$ but all intermetallic phases were transformed to $\mathrm{Ni}_{0.45} \mathrm{Al}_{0.55}, \mathrm{Ni}_{0.58} \mathrm{Al}_{0.42}$, and $\mathrm{Ni}_{3} \mathrm{Al}$ required for high-temperature application by the post heat treatment. ${ }^{5}$ Thus, it could be concluded that higher Ni containing intermetallics were formed when the Al thickness decreased. Quantitative microstructural analysis of acquired micro-laminated composites is plotted in Fig. 2. Type I had higher volume fraction of $\mathrm{Ni}_{0.45} \mathrm{Al}_{0.55}$ and the volume fraction of $\mathrm{Ni}_{0.45} \mathrm{Al}_{0.55}$ increased as Al thickness increased. Generally, it is reported that the diffusion coefficient of $\mathrm{Ni}$ is higher than that of $\mathrm{Al}$ in $\mathrm{NiAl}$ and $\mathrm{Ni}_{3} \mathrm{Al}$ intermetallics. ${ }^{20}$ When the thickness of $\mathrm{Al}$ reaction layer increased, the volume fraction of $\mathrm{Ni}_{0.45} \mathrm{Al}_{0.55}$ will increase due to the relatively limited amount of $\mathrm{Ni}$, which is the main diffusing species in the formation of intermetallics. Type II had higher volume fraction of $\mathrm{Ni}_{0.58} \mathrm{Al}_{0.42}$ and $\mathrm{Ni}_{3} \mathrm{Al}$, and their relative volume fractions were similar, irrespective of $\mathrm{Ni}$

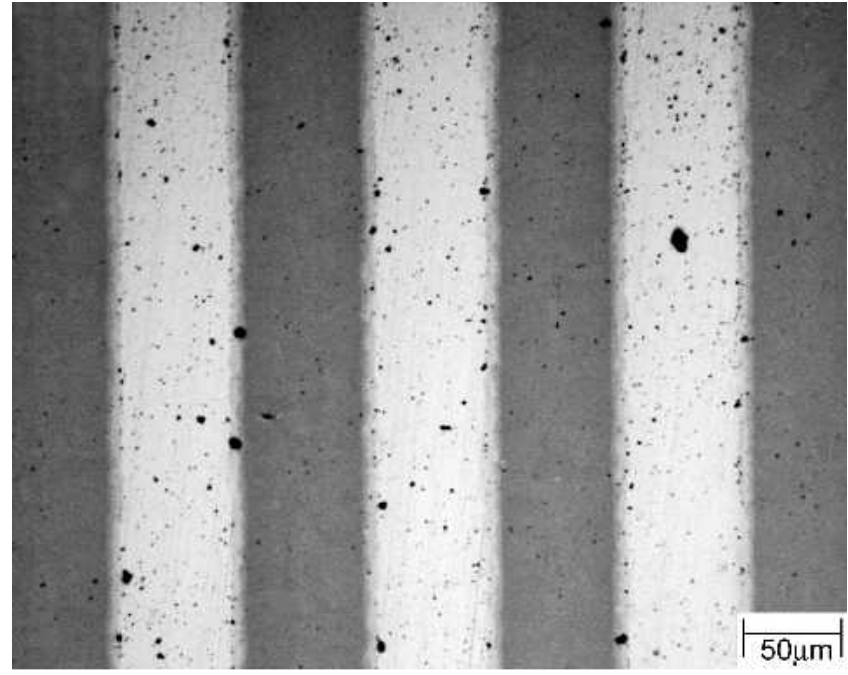

(a)

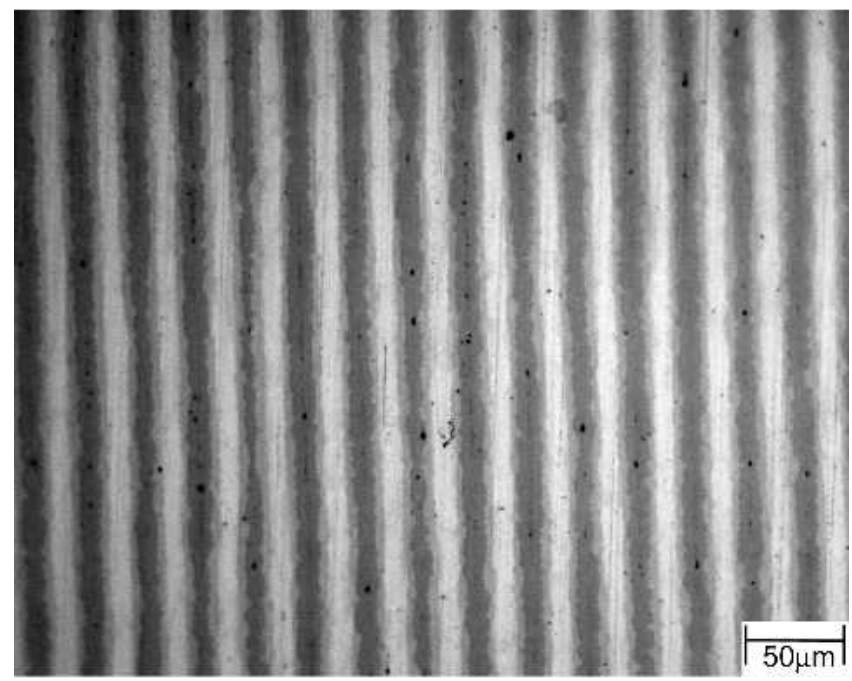

(b)

FIG. 1. Microstructures of intermetallic/metal micro-laminated composites with initial thickness combinations of (a) $100 \mu \mathrm{m} \mathrm{Ni} / 100 \mu \mathrm{m}$ $\mathrm{Al}$ (type I) and (b) $20 \mu \mathrm{m} \mathrm{Ni} / 10 \mu \mathrm{m} \mathrm{Al}$ (type II) prepared by reaction synthesis.

thickness due to the constant $\mathrm{Al}$ reaction layer. The difference of $\mathrm{Ni}$ concentration gradient from the center of Ni layer to the center of intermetallic in two types will highly affect the mechanical properties in terms of intermetallic volume fraction. The discontinuous microvoid, which is inherently present at the intermetallic centerline, will provide the crack nucleation site under applied loading.

\section{B. Tensile properties of $\mathrm{NiAl} / \mathrm{Ni}$ micro-laminated composites}

Under plane strain conditions in parallel direction of lamination, the yield strength of micro-laminated composites according to intermetallic volume fraction can be explained through the rule of mixture (ROM) as follows: 


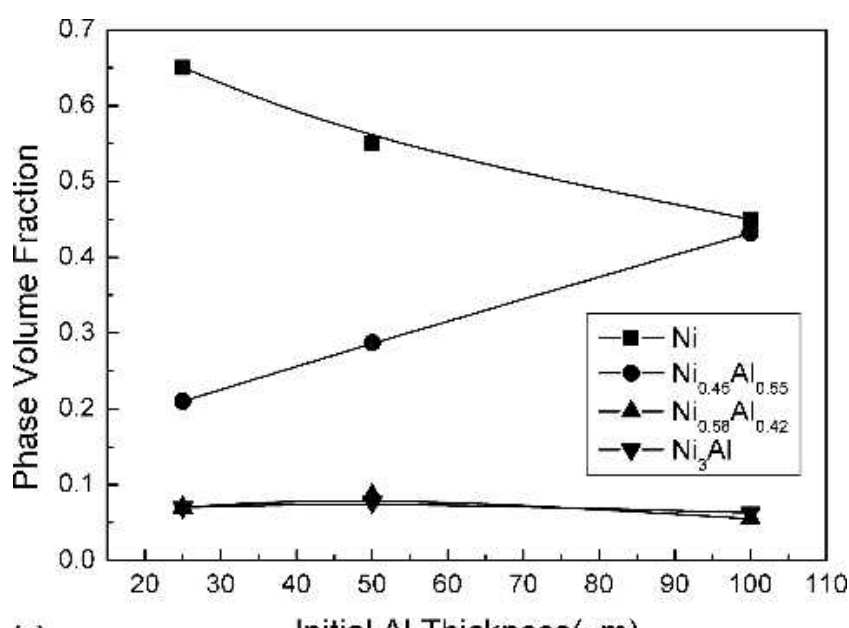

(a)

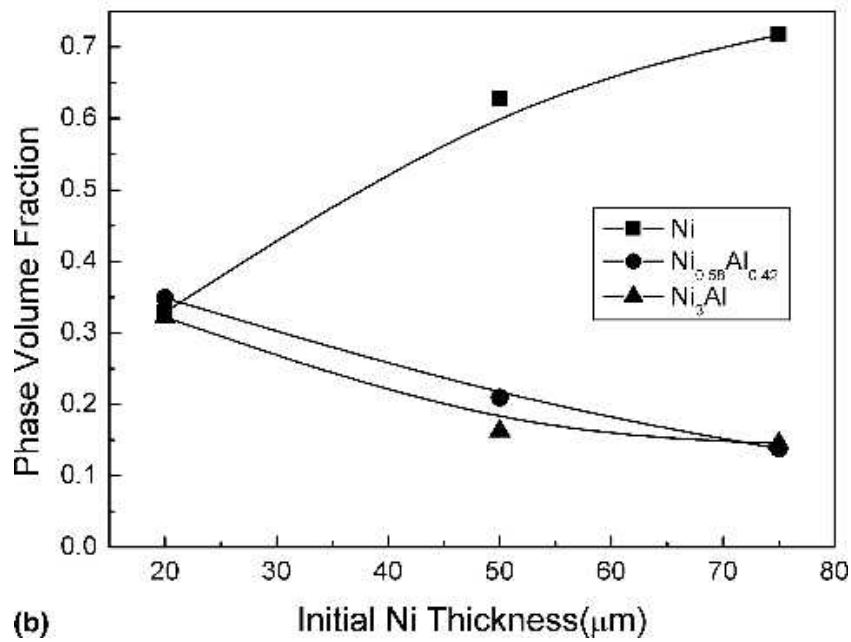

FIG. 2. Quantitative analysis of volume fraction of each phase in (a) type I and (b) type II.

$$
\sigma_{\mathrm{y}}=\sigma_{\mathrm{M}}\left(1-V_{\mathrm{IM}}\right)+\sigma_{\mathrm{IM}} V_{\mathrm{IM}}
$$

Yield strength of pure Ni foil is measured to $93 \mathrm{MPa}$. Therefore, the yield strength of micro-laminated composite can be predicted if the yield strength of NiAl intermetallic is known. However, it is difficult to directly infer the literature value of yield strength of NiAl intermetallic because the mechanical properties of $\mathrm{NiAl}$ intermetallic are highly sensitive to processing condition, microstructure and composition. Figure 3 shows the behavior of $0.2 \%$ offset yield strength of micro-laminated composite according to intermetallic volume fraction. The yield strength of type II depends on intermetallic volume fraction linearly, and the yield strength of intermetallic is assumed to about $440 \mathrm{MPa}$ by Eq. (2), whereas the yield strength of type I does not follow the ROM. Dependence of yield strength of micro-laminated composite on intermetallic volume fraction presumably is related to $\mathrm{Ni}$ concentration of intermetallic. Noebe et al. ${ }^{21}$ reported that the yield strength of NiAl intermetallic changes suddenly near equiatomic concentration. From

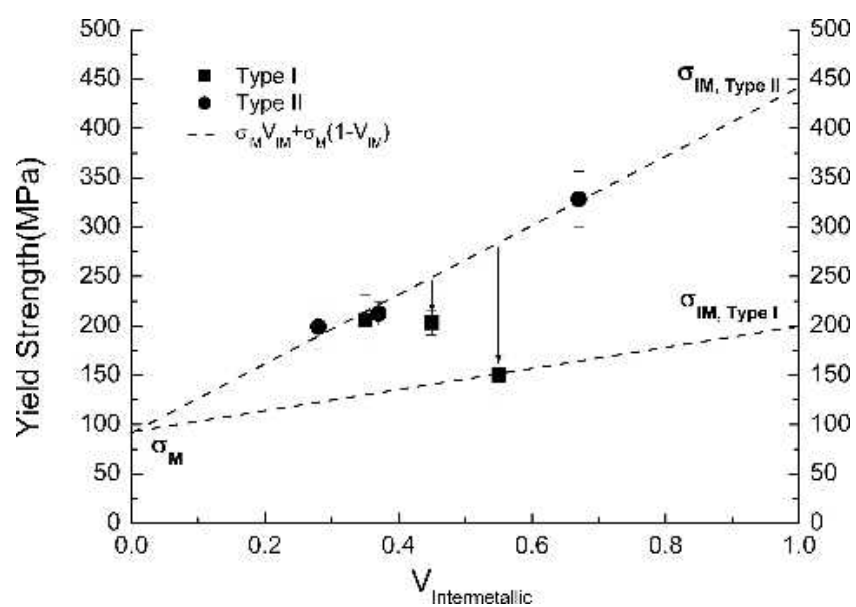

FIG. 3. Yield strength behavior of type I and II micro-laminated composites as a function of intermetallic volume fraction.

Fig. 2, Ni concentration of intermetallic in type II is constant, but that in type I changes due to the different diffusion length of $\mathrm{Ni}$ inside intermetallic. As a result, ROM deviation of yield strength in type I microlaminated composite is caused from the different $\mathrm{Ni}$ concentration of intermetallic. The different strength behaviors of micro-laminated composites lead to the difference of multiple cracking behavior observed in lateral side of tensile-fractured specimens, as shown in Fig. 4(a). In the case of $\mathrm{NiAl} / \mathrm{Ni}$ micro-laminated composites, the crack generally initiates at the brittle intermetallic and multiplies through the entire length of intermetallic layer. ${ }^{22}$ Therefore, the multiple cracking of brittle intermetallic phase can be observed in the presence of extensive plasticity of ductile metal during tensile loading of microlaminated composites. Consider a tensile loaded laminate with center cracked intermetallic layer, as shown in Fig. 5. As suggested by Hwu and Derby, ${ }^{16}$ shear-lag condition is satisfied at the interface of ductile metal layer (M) and brittle intermetallic layer (IM) during tensile loading, and the force equilibrium is made between external applied stress $[\sigma(y))]$ and interfacial shear stress $\left(\tau_{\mathrm{i}}\right)$ within the unit area (dotted area in Fig. 5).

$$
\begin{aligned}
t_{\mathrm{IM}} \mathrm{d}[\sigma(y)] & =\left[2 \tau_{\mathrm{i}}(y)\right] \mathrm{d} y, \\
\sigma(y) & =\frac{2}{t_{\mathrm{IM}}} \int \tau_{\mathrm{i}}(y) \mathrm{d} y .
\end{aligned}
$$

Assuming shear stress at the intermetallic/metal interface is related to the unconstrained yield strength of metal $\left(\sigma_{O}\right)$ in pure shear according to von Mises's criterion, ${ }^{16,23}$ the stress in intermetallic layer is

$$
\tau_{\mathrm{i}}=\frac{\sigma_{0}}{\sqrt{3}},
$$




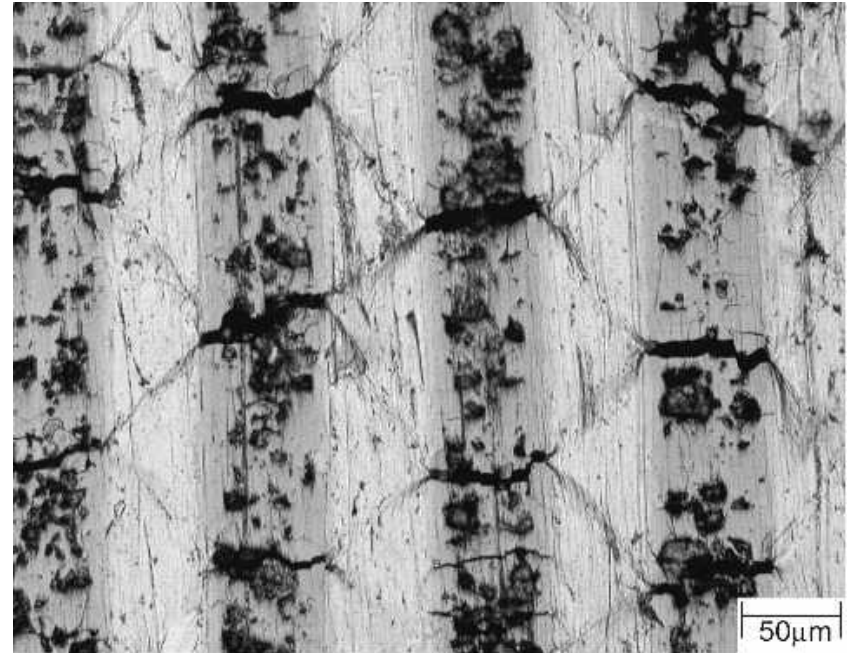

(a)

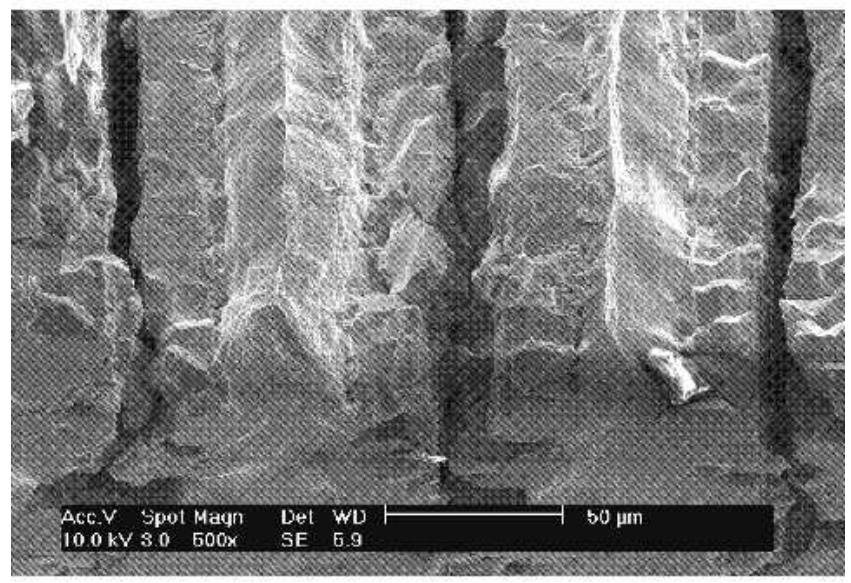

(b)

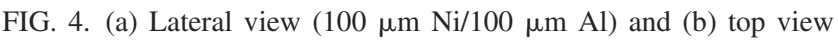
$(100 \mu \mathrm{m} \mathrm{Ni} / 50 \mu \mathrm{m} \mathrm{Al})$ in fractured surface of tensile tested specimens.

$$
\sigma(y)=\frac{2}{\sqrt{3}} \frac{\sigma_{0}}{t_{\mathrm{IM}}} y
$$

Multiple cracking at intermetallic layer will occur when the external stress exceeds the fracture stress of intermetallic $\left(\sigma_{\mathrm{IM}}\right)$, and the multiple cracking distance $\left(l_{\mathrm{R}}\right)$ normalized by intermetallic layer thickness $\left(t_{\mathrm{IM}}\right)$ can be expressed as the ratio of intermetallic fracture stress to unconstrained metal yield stress. Therefore, $\sigma\left(l_{\mathrm{R}}\right)=\sigma_{\mathrm{IM}}$ at $y=l_{\mathrm{R}}$ and we obtain

$$
\frac{l_{\mathrm{R}}}{t_{\mathrm{IM}}}=\frac{\sqrt{3}}{2}\left(\frac{\sigma_{\mathrm{IM}}}{\sigma_{0}}\right) .
$$

Normalized multiple cracking distances of microlaminated composites were measured by optical microscope through all fractured specimen and average value was obtained. Unconstrained metal yield strength was experimentally measured using pure $\mathrm{Ni}$ foil under the

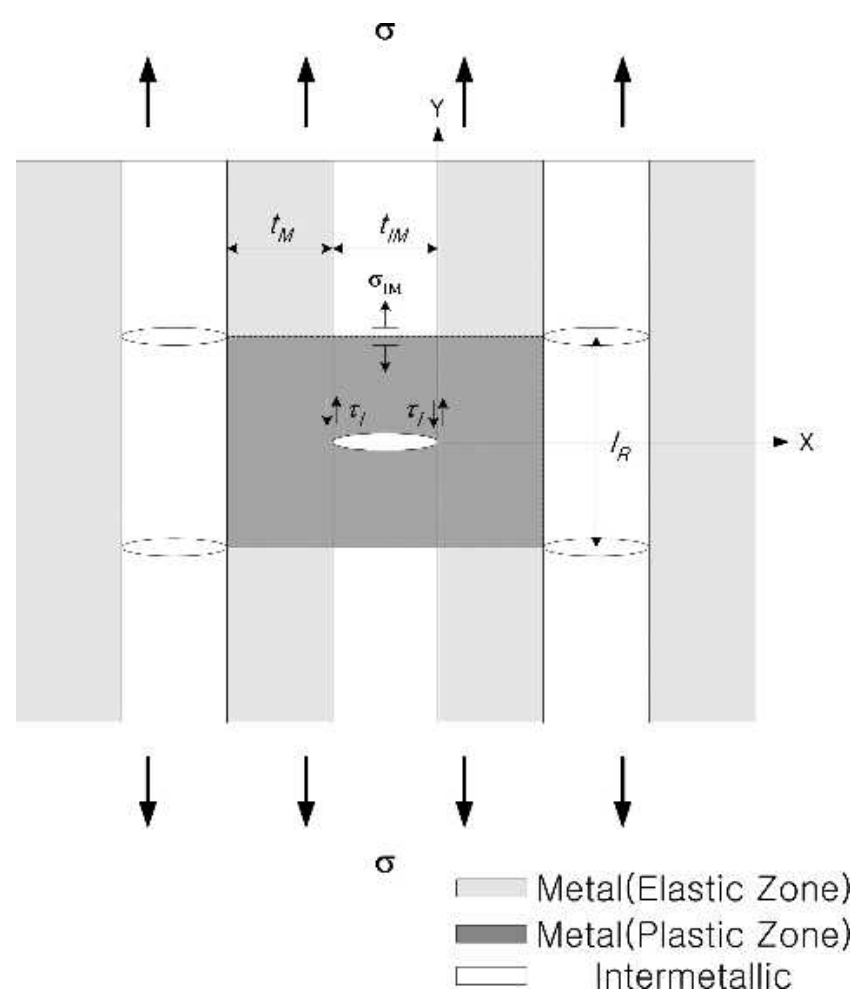

FIG. 5. Schematic diagram showing the stress equilibrium around dot-lined unit area in center cracked laminates during tensile loading.

same annealed condition as the micro-laminated composites. With the experimentally measured normalized multiple cracking distances and unconstrained yield strength of Ni foils known, as shown in Table II, experimental normalized multiple cracking distances were plotted on theoretical curve (Fig. 6), and intermetallic fracture strengths were deduced from Eq. (7). The results of metal/ceramic laminates ${ }^{16}$ were also displayed for comparison. The strength ratio of intermetallic/metal laminates was not constant due to the combination of volume fraction change and concentration gradient of intermetallic layer. From Fig. 6 and Eq. (7), the intermetallic fracture strength was calculated to be 160-210 MPa for type I and 360-560 MPa for type II, and their values are very

TABLE II. Summary of normalized multiple cracking distance of

\begin{tabular}{|c|c|c|c|c|}
\hline & \multicolumn{2}{|c|}{ Initial thickness } & \multirow{2}{*}{$\begin{array}{c}\text { Normalized } \\
\text { multiple } \\
\text { cracking } \\
\text { distance }(\mu \mathrm{m})\end{array}$} & \multirow{2}{*}{$\begin{array}{c}\text { Unconstrained } \\
\text { yield } \\
\text { strength of } \\
\text { pure Ni (MPa) }\end{array}$} \\
\hline & $\mathrm{Ni}(\mu \mathrm{m})$ & $\mathrm{Al}(\mu \mathrm{m})$ & & \\
\hline \multirow[t]{3}{*}{ Type I } & 100 & 25 & 2.0 & 75 \\
\hline & & 50 & 1.7 & \\
\hline & & 100 & 1.6 & \\
\hline \multirow[t]{3}{*}{ Type II } & 75 & 10 & 5.5 & 77 \\
\hline & 50 & & 4.0 & 89 \\
\hline & 20 & & 3.4 & 96 \\
\hline
\end{tabular}
micro-laminated composites and unconstrained metal yield strength. 


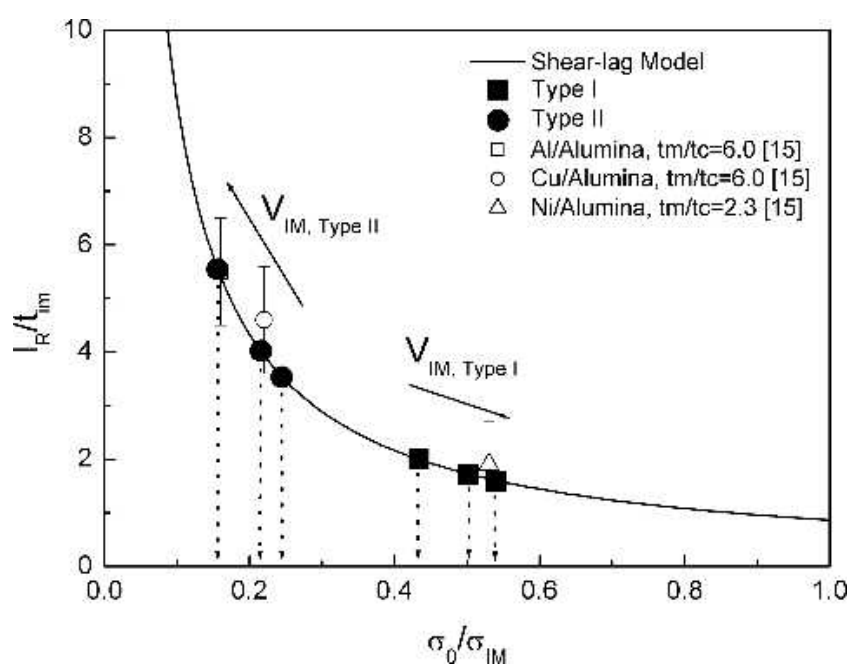

FIG. 6. Relationship between normalized multiple cracking distance and ratio of intermetallic strength to unconstrained metal yield strength according to shear-lag model.

similar to predicted values in ROM. Therefore, the intermetallic fracture strength of type II was higher than two times that of type I, and this must have changed tensile behavior according to intermetallic volume fraction.

The typical fractured surface [Fig. 4(b)] of the microlaminated composites shows that the metal suffers pyramid-shaped ductile fracture by shear lag condition at the interface of intermetallic/metal while the intermetallic shows brittle fracture. It is clear that the shear lag model needs some assumptions but gives the fundamental information for intermetallic fracture strength.

\section{Fracture properties of $\mathrm{NiAl} / \mathrm{Ni}$ micro-laminated composites}

\section{CTOD and $K_{\mathrm{R}}$-curve behavior}

Knowing the yield strength and elastic modulus obtained from the tensile tests of micro-laminated composites, COD is converted to the relevant CTOD using Eq. (6) for SENB specimens. When the intermetallic volume fraction increases, CTOD of micro-laminated composites decreases as shown in Fig. 7. According to the Zok group's results on the toughness of composites, ${ }^{24,25}$ the increase of initiation toughness is related to the increasing volume of material that participates in the plastic deformation ahead of the notch. Therefore, CTOD increase of micro-laminated composite directly depends on the volume fraction increase of metal layer, which is plastic deformed. Type II specimens have higher CTOD values than type I. CTOD results show behavior similar to tensile properties depicted in Fig. 3 and highly dependent on the tensile parameters such as plastic constraints and elastic-plastic properties.

From the tensile and CTOD results, it is apparent that the source of the fracture toughness in the microlaminated composites is associated principally with the

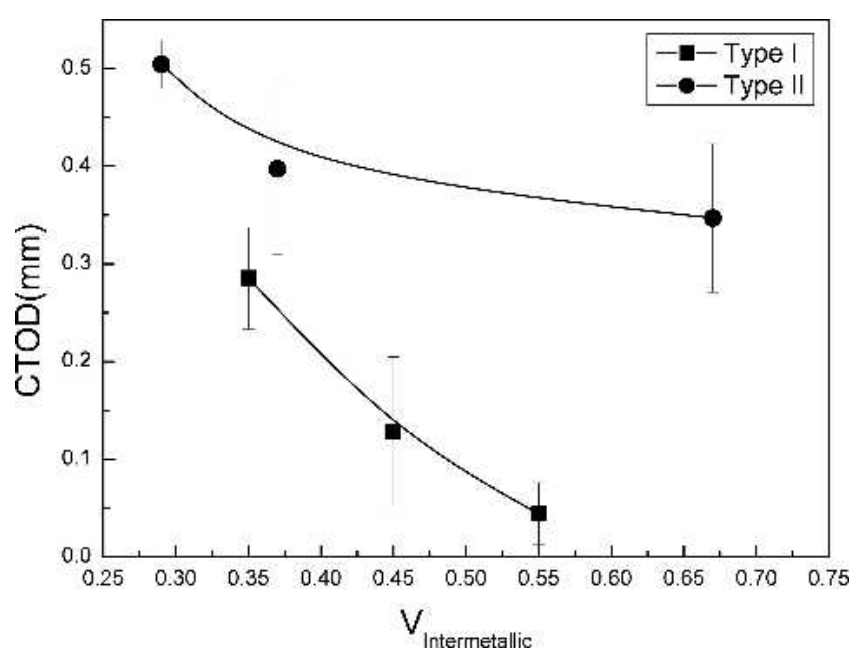

FIG. 7. CTOD values of type I and type II specimens as a function of intermetallic volume fraction.

bridging of a ductile metal layer. However, apparent fracture toughness by CTOD may overestimate the real material properties by large damage zone present ahead of the initial notch. ${ }^{26}$ The contribution to the toughness due to metal layer can be quantitatively analyzed by $K_{\mathrm{R}^{-}}$ curve behavior. Recent work done on $K_{\mathrm{R}}$-curve toughening in other micro-laminated composites shows that LSB more appropriate than the SSB model for application to particle-reinforced composites. ${ }^{27}$ For LSB conditions, the bridging contribution of the metal layer for fracture toughness increase of micro-laminated composites depends on the given traction distribution, crack length, and specimen geometry and can be expressed as ${ }^{28}$

$$
\Delta K=2 \int_{b}^{a} G(x, a, w) \sigma(x) \mathrm{d} x,
$$

where $\sigma(x)$ is the traction as a function of distance $x$ behind the crack tip, $G(x, a, w)$ is the weight function, $a$ is crack length from edge, and $b$ is crack length from edge at the crack initiation. $\sigma(x)$ is related to the constrained flow stress of the metal reinforcement and the assumption of constant traction function appears to be reasonable. ${ }^{27} G(x, a, w)$ for SENB specimen can be defined as shown in Ref. 29. If the bridging contribution is superposed on the intrinsic toughness of micro-laminated composites, the overall toughness $K$ for a given loading condition can be calculated by

$$
K=K_{0}+\Delta K
$$

where $K_{0}$ is toughness at crack initiation. Experimental results on $100 \mu \mathrm{mNi} / 100 \mu \mathrm{m} \mathrm{Al}$ specimen of type I are overlayed on calculated $K_{\mathrm{R}}$-curves in Fig. 8(a), and the bridging traction of micro-laminated composite is positioned to the range of $250-300 \mathrm{MPa}$. The bridging tractions of every other micro-laminated composite are also positioned in the same range. Figure 8(b) summarizes 

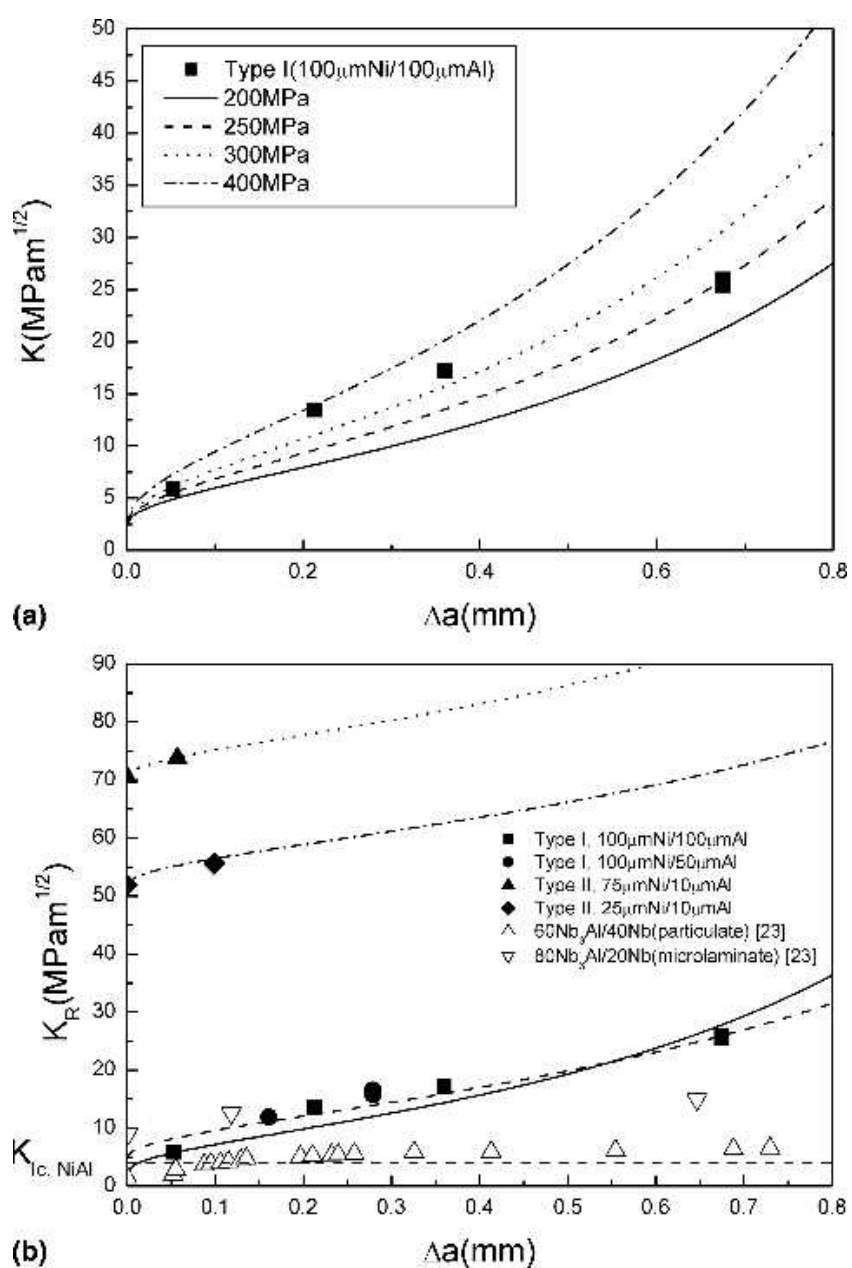

FIG. 8. Comparison of experimentally measured value with calculated $K_{\mathrm{R}}$-curve (a) in type I and (b) summarized results compared with other researchers' results. ${ }^{16,27}$

results of the experimentally measured values compared to calculated $K_{\mathrm{R}}$-curves with the assumption of constant bridging traction $(\sigma=270 \mathrm{MPa})$. In some of specimens, delamination occurred at the center of intermetallic layer and a $K_{\mathrm{R}}$-curve could not be obtained, but all they showed higher fracture toughness than those of monolithic intermetallic $\left(K_{\mathrm{o}, \mathrm{NiAl}}=4 \text { to } 6 \mathrm{MPa} \sqrt{m}\right)^{21}$ and particle or reinforced composites. ${ }^{27}$ Concave types of $K_{\mathrm{R}}$-curves of these laminates prove the fracture toughness following LSB models very well. ${ }^{30}$ The intrinsic fracture toughness $\left(K_{0}\right)$ of type II micro-laminated composites is higher than that of type I micro-laminated composites. The intrinsic fracture toughness depends on the toughness of the matrix and reinforcement and the position of the initial crack. Thus, the higher intrinsic fracture toughness of type II micro-laminated composites is due to the higher strength than type I micro-laminated composites as shown in Fig. 3. CTOD results of Fig. 7 also represent that type II micro-laminated composites would have higher intrinsic fracture toughness. As mentioned previously, bridging traction can be related to the plastic constraint of metal layer, and Hwang and Chang ${ }^{14}$ introduced the plastic constraint parameter $(\rho)$ characterizing the constraint from the adjacent layers in the laminate and reflecting the stress triaxiality. For plane strain conditions based on elastic fracture mechanics, as in Hwang and Chang's study, the normal stress component to the crack direction $\sigma_{y y}$ gives

$$
\sigma_{\mathrm{yy}}=\frac{\sigma_{\mathrm{y}}}{1-2 v}=\rho \sigma_{\mathrm{y}}
$$

where $v$ and $\sigma_{y}$ are the Poisson's ratio and unconstrained yield strength, respectively, of metal. Typical values of $v$ and $\rho$ are 0.33 and 2.94, respectively. Hence, the bridging traction is almost three times the yield stress. If the yield stress is assumed to be near $90 \mathrm{MPa}$ as measured, the bridging stress from the plastic constraint is $270 \mathrm{MPa}$. This value is within the range of bridging stress obtained from experimental $K_{\mathrm{R}}$-curve.

\section{Transition of fracture mode}

Figure 9 shows the microstructures showing the change of fracture modes according to intermetallic volume fraction in type I specimens. When the intermetallic volume fraction increases, the fracture mode changes from the multiple cracking to the single cracking. Shaw et al. ${ }^{13}$ suggested that the fracture mode in the metal/ ceramic multilayer system was determined by the relative magnitudes of the stresses around crack tip depending on the thickness of the metal and ceramic layers, the crack length, the strength distribution of the ceramic, and the flow properties of the metal. They showed that the fracture mode could be changed by calculating the crack tip $\left(\sigma_{\text {tip }}\right)$ and crack wake stress $\left(\sigma_{\text {wake }}\right)$ for the specific specimen geometry. When the metal volume fraction exceeded critical value $\left(f_{\mathrm{m}}>0.6\right)$, stress distribution transition occurred and fracture mode was changed. Hwu and Derby $^{16}$ combined these two stresses to single implicit equation as

$$
\begin{aligned}
1= & \left(\sqrt{\frac{t_{\mathrm{m}}}{t_{\mathrm{c}}}+1}-\sqrt{\frac{t_{\mathrm{m}}}{t_{\mathrm{c}}}}\right)^{-1} f_{\mathrm{I}}\left(\frac{l_{\mathrm{R}}}{t_{\mathrm{c}}}, \frac{l_{\mathrm{R}}}{x}\right) \\
& +\frac{\sigma_{\mathrm{e}}}{\sigma_{\mathrm{c}}} f_{\mathrm{II}}\left(\frac{t_{\mathrm{m}}}{t_{\mathrm{c}}}, \frac{l_{\mathrm{R}}}{t_{\mathrm{c}}}, \frac{x}{t_{\mathrm{c}}}\right), \\
f_{\mathrm{I}}\left(\frac{y}{t_{\mathrm{c}}}, \frac{y}{x}\right)= & \frac{1}{2 \sqrt{2}}\left(\frac{y}{t_{\mathrm{c}}}\right)^{1 / 2} \int_{\pi / 2}^{\pi / 2+\arctan \left(y / t_{\mathrm{c}}\right)^{-1}} \\
& \cos e c^{2} \theta \cos \left(\frac{\theta}{2}\right) \\
& {\left[1+\sin \left(\frac{\theta}{2}\right) \cos \left(\frac{3 \theta}{2}\right)\right] \mathrm{d} \theta, }
\end{aligned}
$$




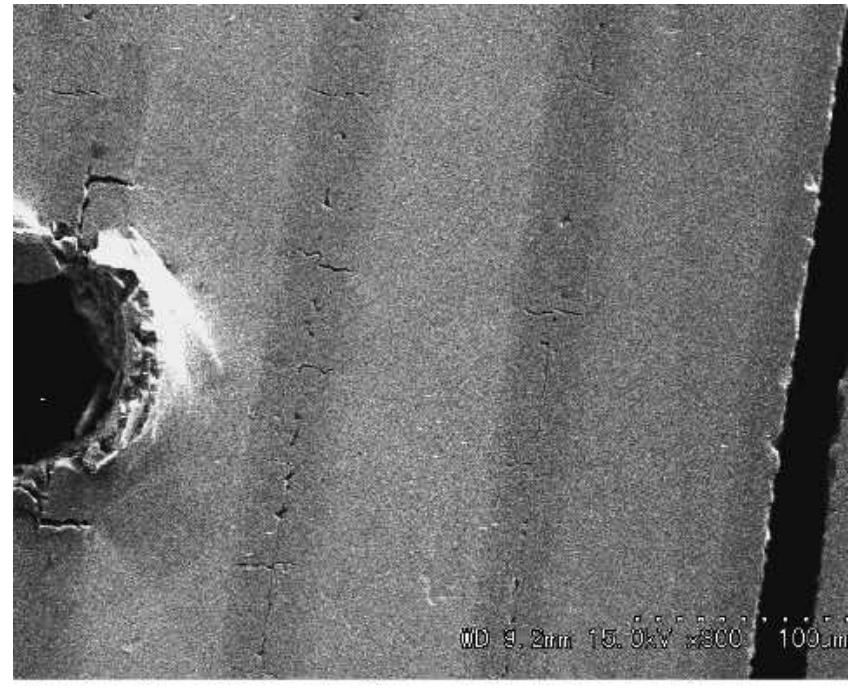

(a)

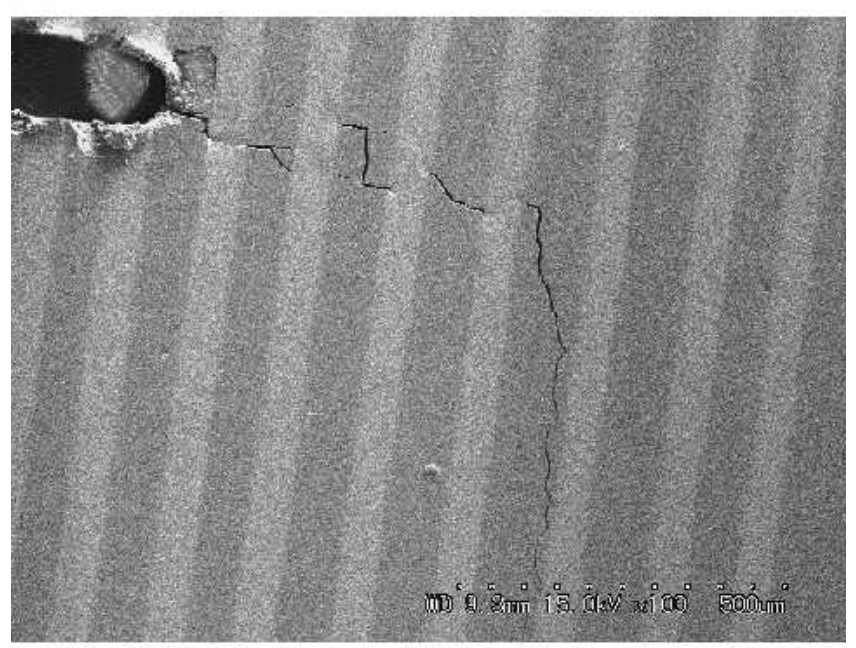

(b)

FIG. 9. Microstructures showing the change of fracture mode from

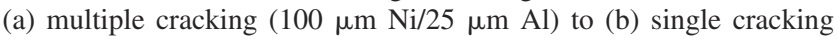
$(100 \mu \mathrm{m} \mathrm{Ni} / 100 \mu \mathrm{m} \mathrm{Al})$ as intermetallic volume fraction increases in type I micro-laminated composites.

$f_{\mathrm{II}}\left(\frac{t_{\mathrm{m}}}{t_{\mathrm{c}}}, \frac{l_{\mathrm{R}}}{t_{\mathrm{c}}}, \frac{x}{t_{\mathrm{c}}}\right)=\frac{1}{\pi} \int_{-1}^{0}(\alpha+\sin \alpha \cos \phi) \mathrm{d}\left(x / t_{\mathrm{c}}\right)$,

where $\sigma_{\mathrm{e}}, \sigma_{\mathrm{c}}, t_{\mathrm{m}}, t_{\mathrm{c}}$ are metal bridging stress, ceramic fracture strength, metal thickness, and ceramic thickness. $l_{\mathrm{R}} / t_{\mathrm{c}}$ has the same meaning as Eq. (7) defined under shear lag conditions at the interface of metal/intermetallic. The conditions for dominant cracking mode were thus expressed: when $\sigma_{\text {tip }}<\sigma_{\mathrm{c}}$ and $\sigma_{\text {wake }}=\sigma_{\mathrm{c}}$, multiple cracking dominates, and when $\sigma_{\text {tip }}=\sigma_{\mathrm{c}}$ and $\sigma_{\text {wake }}<\sigma_{\mathrm{c}}$, single cracking dominates.

In the case of metal/intermetallic micro-laminated composites system, this governing equation can also be applied because we already verified the validity of linear elastic fracture mechanics and shear lag condition by $K_{\mathrm{R}}$-curve and tensile tests. Experimentally measured

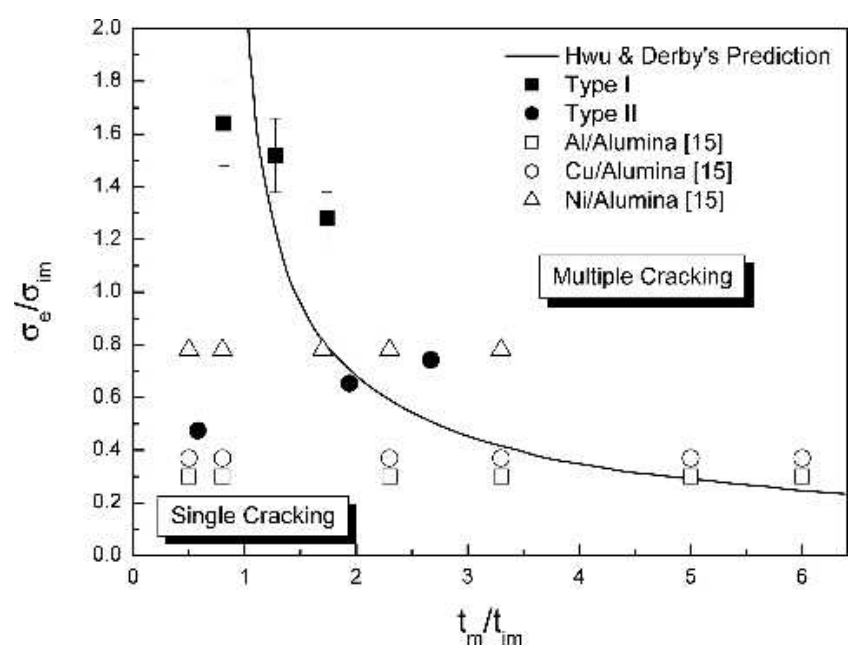

FIG. 10. Fracture map showing the multiple cracking and macroscopic single cracking.

relative thickness ratio of metal/intermetallic and ratio of bridging stress of metal to intermetallic fracture stress are superimposed on the curve calculated by Eq. (11) and displayed in Fig. 10. The apparent fracture mode is in good agreement with the theoretical predictions even though the strength ratio of metal and intermetallic is not constant due to the gradient microstructure of intermetallic/metal laminates. As a result, the fracture properties of intermetallic/metal laminates also are affected by the concentration gradient of intermetallic layer.

\section{CONCLUSIONS}

Microstructures of two types of micro-laminated composites fabricated by reaction synthesis showed different concentration gradient and volume fraction depending on initial foil thickness. The different microstructure led to the different tensile strength behavior according to intermetallic volume fraction. Multiple cracking during tensile loading of micro-laminated composites could be related to the shear-lag condition satisfied at the intermetallic/metal interface. The intermetallic fracture strength deduced from the shear-lag analysis was similar to the results obtained by $\mathrm{ROM}$ analysis.

It was confirmed by CTOD and tensile behavior that the fracture toughness enhancement of intermetallic/ metal micro-laminated composites was due to bridging traction by ductile metal layer. $K_{\mathrm{R}}$-curve test results showed higher and increasing fracture toughness of the micro-laminated composites than the monolithic intermetallic, and the bridging traction based on LSB model was estimated to be 250-300 MPa, which was about three times of yield strength of annealed pure $\mathrm{Ni}$ foils. Fracture mode transitions from single to multiple fracture in intermetallic/metal micro-laminated composites were explained by a combined model of LEFM and shear lag model as applied previously in a metal/ceramic system. 
Mechanical properties of intermetallic/metal laminates were more affected by concentration gradient than metal/ ceramic laminates with unique interfaces, resulting of the variable relative strength of metal and intermetallic.

\section{ACKNOWLEDGMENTS}

This project was supported by the Korea Institute of Science and Technology Evaluation and Planning under contract M1-0105-00-0023. The authors gratefully acknowledge the assistance of Mr. Nambu Shoichi at The University of Tokyo for fracture tests.

\section{REFERENCES}

1. G.S. Was and T. Foecke: Deformation and fracture in microlaminates. Thin Solid Films 286, 1 (1996).

2. K.S. Kumar and G. Bao: Intermetallic-matrix composites: An overview. Comp. Sci. Technol. 52, 127 (1994).

3. M. Enoki, A. Ohta, D.S. Chung, M. Watanabe, and T. Kishi: Crack propagation behavior of Ti/Ti-Al layered materials. J. Jpn. Inst. Metals 64, 1076 (2000).

4. D.S. Chung, M. Enoki, and T. Kishi: Microstructural analysis and mechanical properties of in situ $\mathrm{Nb} / \mathrm{Nb}$-aluminide layered materials. Sci. Technol. Adv. Mater. 3, 129 (2002).

5. H.Y. Kim, D.S. Chung, and S.H. Hong: Reaction synthesis and microstructures of NiAl/Ni micro-laminated composites. Mater. Sci. Eng. A 396, 376 (2005).

6. D.S. Chung, J.K. Kim, and M. Enoki: In-situ fabrication and fracture characteristics of structural gradient $\mathrm{Ni} / \mathrm{Ni}$-aluminide/Ti/Tialuminide layered materials. Mater. Sci. Forum 475-479, 1521 (2005).

7. U. Anselmi-Tamburini and Z.A. Munir: The propagation of a solid-state combustion wave in Ni-Al foils. J. Appl. Phys. 66, 5039 (1989).

8. J.C. Rawers, D.E. Alman, and J.A. Hawk: Overview: Layered metal/intermetallic composites formed by SHS reactions. Int. J. Self-Prop. High Temp. Synth. 2(1), 12 (1993).

9. D.E. Alman, J.C. Rawers, and J.A. Hawk: Microstructural and failure characteristics of metal-intermetallic layered sheet composites. Metall. Mater. Trans. A 26A, 589 (1995).

10. T.S. Dyer and Z.A. Munir: The synthesis of nickel aluminides by multilayer self-propagating combustion. Metall. Mater. Trans. B 26B, 603 (1995).

11. A. Rohatgi, D.J. Harach, K.S. Vecchio, and K.P. Harvey: Resistance-curve and fracture behaviour of $\mathrm{Ti}-\mathrm{Al}_{3} \mathrm{Ti}$ metallicintermetallic laminate (MIL) composites. Acta Mater. 51, 2933 (2003).
12. H.C. Cao and A.G. Evans: On crack extension in ductile/brittle laminates. Acta Metall. Mater. 39, 2997 (1991).

13. M.C. Shaw, D.B. Marshall, M.S. Dadkhah, and A.G. Evans: Cracking and damage mechanisms in ceramic/metal multilayers. Acta Metall. Mater. 41, 3311 (1993).

14. Y. Huang, H.W. Zhang, and F. Wu: Multiple cracking in metalceramic laminates. Int. J. Solids Struct. 31, 2753 (1994).

15. Y. Huang and H.W. Zhang: The role of metal plasticity and interfacial strength in the cracking of metal/ceramic laminates. Acta Metall. Mater. 43, 1523 (1995).

16. K.L. Hwu and B. Derby: Fracture of metal/ceramic laminates-I. transition from single to multiple cracking. Acta Metall. Mater. 47, 529 (1999).

17. ASTM E399-90, Annual Book of ASTM Standards, Vol. 08.07. (ASTM International, 1991), p. 408.

18. ASTM E1290-93, Annual Book of ASTM Standards, Vol. 08.08. (ASTM International, 1993), p. 828.

19. P. Zhu, J.C.M. Li, and C.T. Liu: Reaction mechanism of combustion synthesis of NiAl. Mater. Sci. Eng. A 329, 57 (2002).

20. H. Numakura, T. Ikeda, H. Nakajima, and M. Koiwa: Diffusion in $\mathrm{Ni}_{3} \mathrm{Al}, \mathrm{Ni}_{3} \mathrm{Ga}$ and $\mathrm{Ni}_{3}$ Ge. Mater. Sci. Eng. A 312, 109 (2001).

21. R.D. Noebe, R.R. Bowman, and M.V. Nathal: Physical and mechanical properties of the $\mathrm{B} 2$ compound NiAl. Int. Mater. Rev. 38(4), 193 (1993).

22. J. Rawers and K. Perry: Crack initiation in laminated metalintermetallic composites. J. Mater. Sci. 31, 3501 (1996).

23. G.E. Dieter: Mechanical Metallurgy, 2nd ed. (McGraw-Hill Book Co., New York, 1976), p. 77.

24. S.V. Kamat, J.P. Hirth, and F.W. Zok: Effects of notch root radius on crack initiation and growth toughnesses of a cross-ply Ti-6Al-4V/SiC composite. Acta Mater. 44, 1831 (1996).

25. J.Y. Shen, J.P. Hirth, F.W. Zok, and J.A. Heathcote: Effect of notch root radius on the initiation toughness of a C-fiber/SiCmatrix composite. Scripta Mater. 38(1), 15 (1998).

26. F. Zok and C.L. Hom: Large scale bridging in brittle matrix composites. Acta Metall. Mater. 38, 1895 (1990).

27. D.R. Bloyer, K.T.V. Rao, and R.O. Ritchie: Resistance-curve toughening in ductile/brittle layered structures: Behavior in $\mathrm{Nb} /$ $\mathrm{Nb}_{3} \mathrm{Al}$ laminates. Mater. Sci. Eng. A 216(1-2), 80 (1996).

28. B.N. Cox and D.B. Marshall: Stable and unstable solutions for bridged cracks in various specimens. Acta Metall. Mater. 39, 579 (1991).

29. H. Tada, P. Paris, and G. Irwin: The Stress Analysis of Cracks Handbook, 2nd ed. (Paris Prod. Inc., St. Louis, MO, 1985).

30. D.R. Bloyer, K.T.V. Rao, and R.O. Ritchie: Fracture toughness and R-curve behaviour of laminated brittle-matrix composites. Metall. Mater. Trans. A 29A, 2483 (1998). 